\title{
Correction to: Abstracts of the 15th International Congress of the European Geriatric Medicine Society
}

\author{
Editorial Office of European Geriatric Medicine ${ }^{1}$
}

Published online: 6 November 2020

(c) European Geriatric Medicine Society 2020

\section{Correction to: Eur Geriatr Med (2019) 10 (Suppl 1):S1-S325 https://doi.org/10.1007/s41999-019-00221-0}

The Editorial Office of EGM has been informed by the author of abstract P-302 that the list of authors published in this abstract was not correct. The correct list of the authors of the abstract P-302 is

Estera Wieczorek $^{1,2}$, Milena Pavlova $^{1}$

${ }^{1}$ Maastricht University, Department of Health Services Research, The Netherlands
${ }^{2}$ Jagiellonian University Medical College, Institute of Public Health, Department of Health Economics and Social Security, Krakow, Poland

Publisher's Note Springer Nature remains neutral with regard to jurisdictional claims in published maps and institutional affiliations.

The original article can be found online at https://doi.org/10.1007/ s41999-019-00221-0.

Editorial Office of European Geriatric Medicine

https://www.springer.com/journal/41999 